\title{
SOLVING OPTIMAL GENERATION DISPATCH PROBLEM IN POWER NETWORKS THROUGH PSO AND LAMBDA ITERATION TECHNIQUES
}

\author{
A. S. Alayande ${ }^{1}$, J. T. Olowolaju ${ }^{2}$ and I. K. Okakwu ${ }^{3, *}$

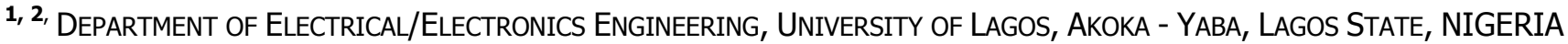 \\ 3, DePARTMENT OF ElECTRICAL/EleCtronics ENGINEering, UNIVERSITY OF BENIN, BENIN CITY, EDO STATE, NIGERIA \\ E-mail addresses: ${ }^{1}$ aalayande@unilag.edu.ng, ${ }^{2}$ joshuaolowolaju@gmail.com, ${ }^{3}$ igokakwu@yahoo.com
}

\begin{abstract}
Efficient solution to the problem of economic dispatch of network generators has been a growing concern to power system utilities in recent times. This is aimed at determining the optimal allocation of the total network demand among the available generating units such that the total cost of generation is reduced while maintaining an acceptable generation output subject to specified system constraints. This paper, therefore, attempts to resolve this issue from two main perspectives; Lambda Iterative-based approach and Particle Swarm Optimization (PSO) technique. The theoretical backgrounds as well as the mathematical formulations for the two approaches are presented. The standard IEEE 14-Bus, IEEE 30-Bus and the Indian 62-Bus networks are used as case studies to present illustrative examples for the approach. The simulation results obtained using the two approaches are presented and compared. The comparisons of the results obtained show that the two approaches are suitable for providing efficient solutions to economic dispatch problems in large power networks.
\end{abstract}

Keywords. economic dispatch; network demands; lamda iterative; particle swarm optimization; generation cost

\section{INTRODUCTION}

Modern power systems are faced with challenges arising from various factors which include existence of rated limits of generator's power output, varying fuel costs of power plants, the need for energy balance, and unequal distance between generation plants and load centres [1,2]. Engineers and power utilities are therefore concerned as this has hampered the provision of sustainable, adequate, reliable and efficient electricity supply at the minimum possible cost. This can be duly addressed by considering optimal generation dispatch [3]. Optimal dispatch is the process of allocating the required load demand between the available generation units such that the cost of operation is at a minimum $[4,5]$. It aims at minimizing the generation cost rate to meet the load demand of a power system over some appropriate period while satisfying various operating constraints. As it is of high importance to reduce the operating cost, electric utilities seek ways to minimize unit cost of available power generation without jeopardizing the integrity of the networks in terms of reliability and network security $[2,3]$. Economic load dispatch is one method of achieving this objective. It is a method of allocating active power outputs to available generation units with the aim of keeping generation cost at minimum value in compliance with all constraints of the network. Solution to economic dispatch optimization drives at operating our power system in a manner that minimizes the costs on generation. The best way to minimize the current generator operating costs is determined by optimal dispatch $[6,7]$.

Several existing approaches for solving optimal dispatch problem have been presented in the literature. For instance, the author of [8] presented a solution to economic dispatch problem based on the Newton's method and using a closed form expression for the calculation of the Lambda. In [9] and [10], a modified lambda-iteration method is proposed. Reference [3] formulated and provided solution to the economic dispatch problem of five generators at the Ughelli Power Station, Nigeria using Lagrange multiplier method. Lambda technique is employed by 
[4] in an optimization analysis of the economic distribution of loads on the existing and expanded thermal plants in Nigeria electricity grid. Result revealed showed an optimal operation of the plants with an improvement in savings.

Particle Swarm Optimization (PSO) method is proposed and presented in [11] for solving the Economic Dispatch (ED) problem in power systems considering generator constraints. The experimental results revealed that solution of higher quality to $E D$ problems are obtainable using the proposed method. The authors suggested a Modified PSO (MPSO) technique to deal with the equality and inequality constraints in the ED problems. Also, constraint treatment mechanism is devised in such a way that the dynamic process inherent in the conventional PSO is preserved. The authors of [12] developed a $\Theta-$ Particle Swarm Optimization ( $\Theta-P S O)$ based algorithm. Constraints such as transmission losses, ramp rate limits were easily taken care of by the methodology. An improvement in PSO to Particle Swarm Optimization with Constriction Factor Approach (PSOCFA), Particle Swarm Optimization with Inertia Weight Factor Approach (PSOIWA) and Particle Swarm Optimization with Constriction Factor and Inertia Weight Factor Approach (PSOCFIWA) for providing efficient solution to ED problems have also been documented in the open literature [13]. The various algorithms were applied to three, six and fifteen generator ELD problem while given a consideration to ramp-rate limits constraint in the problem formulation. The results obtained showed that PSOIWA approach gives the best global optimum solution with less computation time than the PSO, PSOCFA and PSOCFIWA techniques. Furthermore, it is also revealed that PSOIWA algorithm converges to optimal fuel cost faster. The authors of [2] employed PSO algorithm to solve the ELD problem of the Nigeria thermal power stations. The results obtained showed that the PSO technique minimizes the total production cost and transmission losses.

Other modern meta-heuristic techniques such as Genetic Algorithm (GA) and Differential Evolution (DE) [14], constrained elitist genetic algorithm (CEGA) [1], GA-API [15], Improved Tabu Search algorithm (ITS) [16] have also been developed for solving ED problems in recent times. Happ in [17] presented a solution by the use of the Jacobian matrix, a method using an alternative Jacobian matrix was presented in $[18,19]$ used a direct search method (DSM) to handle a number of inequality and equality constraints and units with any kind of fuel costs functions. A simulated annealing (SA) technique for the determination of the global or near global optimum dispatch solution is developed by the authors of reference [20]. In [21], the connections between Automatic Generation Control (AGC) and Economic Dispatch (ED) are studied. In [22], Levy flights based Moth-Flame optimization (MFO) Algorithm, a novel bio-inspired optimization algorithm based on the navigation strategy of Moths in universe, is developed. The authors of [23] presented a hybrid algorithm an amalgamation of three well known meta-heuristic algorithms namely the $A C O, A B C$ and $\mathrm{HS}$ and hence it was named the ACO-ABC-HS algorithm. In reference [24], a vortex search algorithm for solving complex economic load dispatch problem is proposed.

Although, substantial contributions have been made in providing efficient solution to the ED problem through several methods in the open literature, a comparative study between some of the efficient techniques when considering large power systems have not been considered. This paper attempts to study the ED problems, from the economical point of view, and provides a comparative analysis based on Lambda-Iterative Technique and Particle Swarm Optimization Technique.

The remainder of the paper is structured as follows: Section 2 presents the theoretical framework as well as the mathematical formulations for the two approaches considered in this paper. In section 3, a brief description of the case studies is presented for numerical illustrations. The results obtained are presented, discussed and compared in section 4 while the study is concluded in section 5 .

\section{THEORETICAL BACKGROUND AND MATHEMATICAL FORMULATIONS}

\subsection{Economic Dispatch Problem Formulation}

Consider a power network with $\mathrm{n}$ number of generator plants and a given power demand of $p_{D}$. Each plant $i$, has a cost-rate curve that gives the cost $C_{I}$ in $\$ /$ hour as a function of its generation level $P_{G i}$ (the 3phase power). The actual power generation $P_{G i}$ is to be allocated to generators so that total cost of generation is minimized. The economic dispatch problem can be addressed as shown below.

The cost function is expressed as a quadratic function of active power.

$$
C_{i}\left(P_{G i}\right)=a_{i} P_{G i}^{2}+b_{i} P_{G i}+C_{i}
$$

The total system cost is therefore given by 


$$
C_{T}=\sum_{i=1}^{n} C_{i}\left(P_{G i}\right)
$$

The objective function to be minimized is given in equation (2). Hence, the fundamental generation dispatch problem can be formulated mathematically as a minimization problem of the total fuel cost of all available and committed plants. Mathematically,

$$
\text { Minimizing } \sum_{i=1}^{n} C_{i}\left(P_{G i}\right)
$$

where $C_{i}\left(P_{G i}\right)$ is the fuel cost expression for the $i^{\text {th }}$ generator unit.

The objective function is to be minimized subject to two basic kinds of constraints.

i. The power balance equality: In regards to power balance, it must be the case that the total generation equals the total demand $P_{D}$.

$$
\sum_{i=1}^{n} P_{G i}=P_{D}
$$

ii. Active power constraints: Physical constraints exist on generation levels as generators cannot exceed their maximum capabilities, represented by $P_{G i}^{\max }$. And clearly, they cannot operate below 0 . Most units actually cannot operate at 0 ; as a result, we will denote the minimum as $P_{G i}^{\min }$. Therefore, the generation limits are represented by

$$
P_{G i}^{\min } \leq P_{G i} \leq P_{G i}^{M a x} \quad(i=1,2, \ldots, n)
$$

For minimizing (or maximizing) a function the Lagrange multiplier $\lambda$ is used. Using this method an augmented function is defined as[25]

$$
L\left(P_{G i}, \lambda\right)=C_{i}\left(P_{G i}\right)+\lambda\left(P_{D}-\sum_{i=1}^{n} P_{G i}\right)
$$

To minimize cost of generation $C_{i}\left(P_{G i}\right)$ subject to energy balance constraint, a necessary condition is that the partial derivative of the Lagrange function defined by $L=L\left(P_{G i}, \lambda\right)$ with respect to each of its arguments must be zero. Hence, the necessary optimization problems conditions are

$$
\frac{\partial L\left(P_{G i}, \lambda\right)}{\partial P_{G i}}=\frac{\partial C_{i}\left(P_{G i}, \lambda\right)}{\partial P_{G i}}-\lambda=0
$$

And

$$
\frac{\partial L\left(P_{G i}, \lambda\right)}{\partial P_{G i}}=P_{D}-\sum_{i=1}^{n} P_{G i}=0
$$

From equation (7),

$$
\frac{\partial C_{i}\left(P_{G i}, \lambda\right)}{\partial P_{G i}}=\lambda \quad(i=1,2, \ldots, n)
$$

The above is called the co-ordination equation. Hence, incremental cost of the $i^{\text {th }}$ generator becomes:

$$
\frac{\partial C_{i}\left(P_{G i}, \lambda\right)}{\partial P_{G i}}=2 a_{i} P_{G i}+b_{i}
$$

Comparing (9) and (10), we get

$$
2 a_{i} P_{G i}+b_{i}=\lambda
$$

Arranging the equation, we get

$$
P_{G i}=\frac{\lambda-b_{i}}{2 a_{i}} \quad(i=1,2, \ldots, n)
$$

Substituting this value of $P_{G i}$ in (8), we get

$$
\sum_{i=1}^{n} \frac{\lambda-b_{i}}{2 a_{i}}=P_{D}
$$

Alternatively,

$$
\lambda=\frac{P_{D}+\sum_{n=1}^{n} \frac{b}{2 a_{i}}}{\sum_{n=1}^{n} \frac{1}{2 a_{i}}}
$$

Hence, $\lambda$ is found out with the help of (14) and $P_{G i}$ is found using (12).

The simple algorithm for solving economic dispatch problems is as follows[9]

1. Assume an initial value for $\lambda$

2. Compute $P_{G i}(i=1,2, \ldots, n)$ using (11);

3. Check the limit of generators, to ensure that none of the $P_{G i}$ values computed goes beyond the limits specified in (5);

4. If $P_{G i} \geq P_{G i}^{\max }$, set $P_{G i}=P_{G i}^{\max }$, but if $P_{G i} \leq P_{G i}^{\min }$ , set $P_{G i}=P_{G i}^{\min }$;

5. Compute $\Delta P$ using (12);

6. Compute $\Delta \lambda(k)$ using (13);

7. If $\Delta \lambda(k) \leq$ Tolerance value, stop and display $P_{G i}, \lambda$. Otherwise, go to step 8

8. $\lambda$ is updated using $\lambda(k+1)=\lambda(k)+\Delta \lambda(k)$

9. Go to step 2

10 Stop

\subsection{Marginal (Incremental) Cost Curve}

The cost function is expressed as a quadratic function of active power.

$$
C_{i}\left(P_{G i}\right)=a_{i} P_{G i}^{2}+b_{i} P_{G i}+C_{i}
$$

The derivative of the cost curve is the marginal or incremental cost curve. The marginal (incremental) cost is one of the most important quantities in operating a power system. It informs us of the cost of producing the next increment of power (the next $M W$ ). It is a measure of how costly it will be to produce the next increment of power. 


$$
\frac{\partial C_{i}\left(P_{G i}, \lambda\right)}{\partial P_{G i}}=2 a_{i} P_{G i}+b_{i}\left(\frac{\$}{M W h}\right)
$$

\subsection{Particle Swarm Optimization Algorithm}

Particle swarm optimization is a nature-inspired metaheuristic optimization algorithm developed by James Kennedy and Russell Eberhart in 1995. It was inspired by the helping nature of particle (birds, fishes) while searching for food. They search the food by their personal experience $P_{\text {best }}$ and the experience of nearby particles overall experience $G_{\text {best }}$. These experiences are accelerated by two factors $C_{1}$ and $C_{2}$, and two random numbers generated between $[0,1]$ whereas the present movement is multiplied by an inertia factor $\mathrm{W}$ varying between $\left[w_{\min } ; w_{\max }\right]$. Let the position and velocity of the particle in the search space be $\mathrm{x}$ and $\mathrm{v}$ respectively. Each $i^{\text {th }}$ particle is expressed as $x_{i}=\left(x_{i 1}, x_{i 2}, x_{13}, \ldots, x_{i j}\right)$ in the space of $\mathrm{j}$-dimension. The particle keeps track of the best previous position expressed as $P_{i}=$ $\left(P_{i 1}, P_{i 2}, P_{13}, \ldots, P_{i j}\right)$. The index of particle which is best among all the particles in multi-dimensional search space is the global best particle, denoted as $G_{i}$. The modified position and velocity of every particle are computed based on the current velocity and distance from $P_{i j}$ and $G_{j}$, which can be expressed as follows[6]

$$
x_{i j}(t+1)=x_{i}(t)+v_{i j}(t+1)
$$

The updated velocity is expressed as

$$
\begin{gathered}
v_{i j}(t+1)=w \cdot v_{i j}(t)+r_{1} c_{1}\left(P_{i j}(t)-x_{i j}(t)\right) \\
+r_{2} c_{2}\left(G_{j}(t)-x_{i j}(t)\right)
\end{gathered}
$$

The flow chart for Particle swarm optimization is as follows:

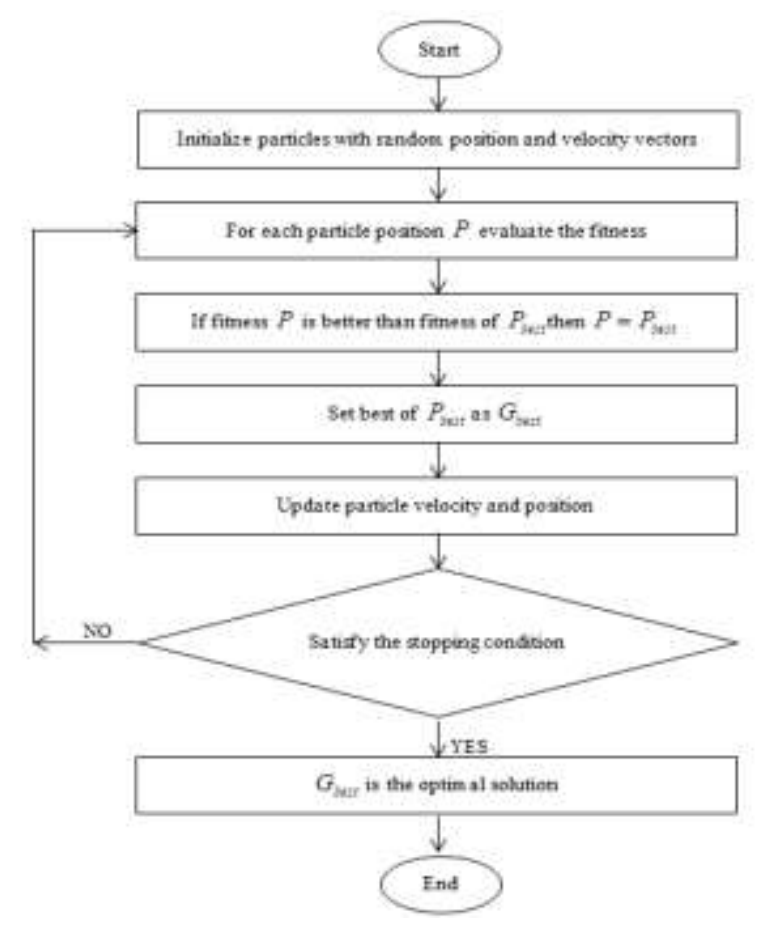

Figure 1:Flow chart for particle swarm optimization

\section{NUMERICAL ILLUSTRATIONS}

This section presents numerical examples using three different case studies; IEEE 14-bus, IEEE 30-bus and Indian 62-bus systems [26]. The IEEE 14-bus system comprises 3 generators and 11 loads. The IEEE 30bus system comprises 6 generators and 6 loads. The Indian 62-bus system comprises 19 generators and 19 loads. For Power demand of $P_{G}$, the IEEE 14-bus system has a generation limit of $50 W M \leq P_{G} \leq$ $290 M W$, the IEEE 30-bus system has generation limit of $0 W M \leq P_{G} \leq 330 M W$ and the Indian 62-bus system has generation limit of $650 W M \leq P_{G} \leq$ $5850 M W$. From the Optimal Dispatch Analysis, the minimum cost of Power generation is determined for a range of Electrical Power Demand with the generation limits. All the simulations are carried out on MATLAB 2016a environment.

Table 1:minimum cost for a range of power demand using the lambda iteration method

\begin{tabular}{cccccc}
\hline POWER DEMAND & $50 \mathrm{MW}$ & $100 \mathrm{MW}$ & $150 \mathrm{MW}$ & $200 \mathrm{MW}$ & $250 \mathrm{MW}$ \\
\hline GEN 1 & 10 & 60 & 110 & 143 & 160 \\
GEN 2 & 20 & 20 & 20 & 37 & 64 \\
GEN 3 & 20 & 20 & 20 & 20 & 26 \\
\hline Minimum Cost & $\$ 366.70$ & $\$ 506.70$ & $\$ 671.70$ & $\$ 858.81$ & $\$ 1059.34$ \\
\hline
\end{tabular}

Table 2: Minimum cost for a range of power demand using the Particle Swarm Optimization method

\begin{tabular}{cccccc}
\hline Power Demand & $50 \mathrm{MW}$ & $100 \mathrm{MW}$ & $150 \mathrm{MW}$ & $200 \mathrm{MW}$ & $250 \mathrm{MW}$ \\
\hline Gen 1 & 10 & 60 & 110 & 143 & 160 \\
Gen 2 & 20 & 20 & 20 & 37 & 64 \\
Gen 3 & 20 & 20 & 20 & 20 & 26 \\
\hline Minimum Cost & $\$ 366.70$ & $\$ 506.70$ & $\$ 671.70$ & $\$ 858.81$ & $\$ 1059.34$ \\
\hline
\end{tabular}




\section{RESULTS AND DISCUSSION}

\subsection{Case Study I: IEEE 14-Bus System}

Figure 2, obtained using the lambda iteration approach displays the power allocation for each generation plant in the IEEE 14-Bus System, for power demand ranging from $50 \mathrm{MW}$ to $250 \mathrm{MW}$. The minimum cost obtained using the lambda iteration approach is as presented in Table 1. Figure $3-7$, displays the minimum cost obtained using the PSO method on the IEEE 14-Bus System, for power

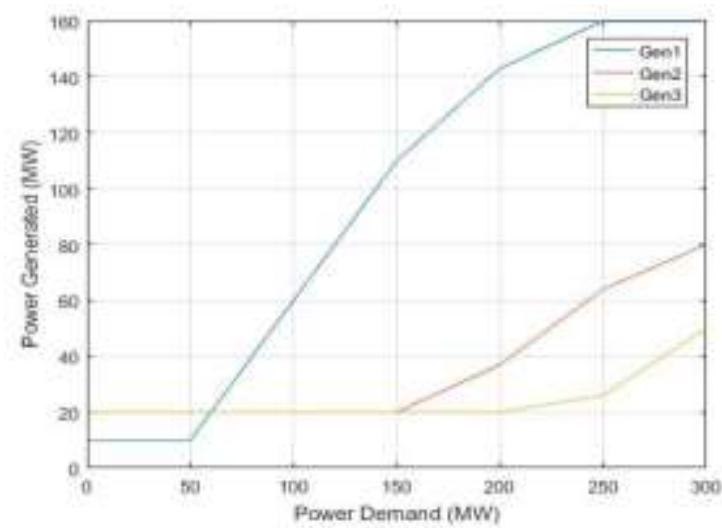

Figure 2:Generator Scheduling for IEEE 14-Bus System

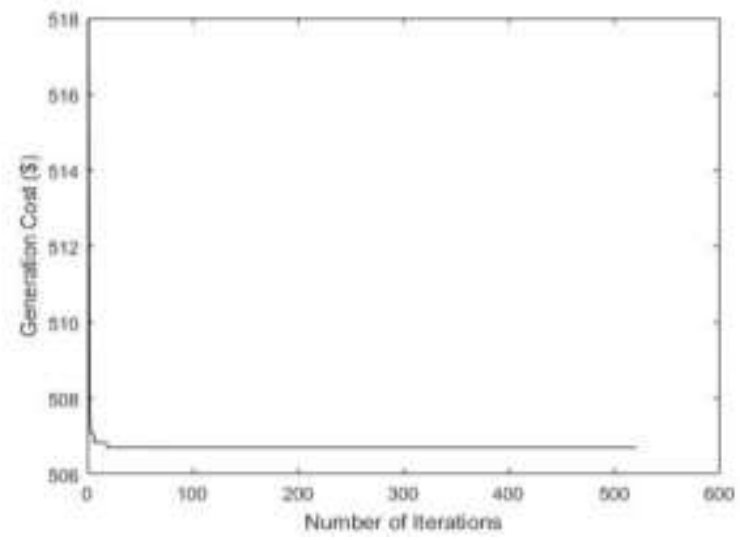

Figure 4: PSO convergence characteristics for real power demand of 100MW for the IEEE 14-bus network

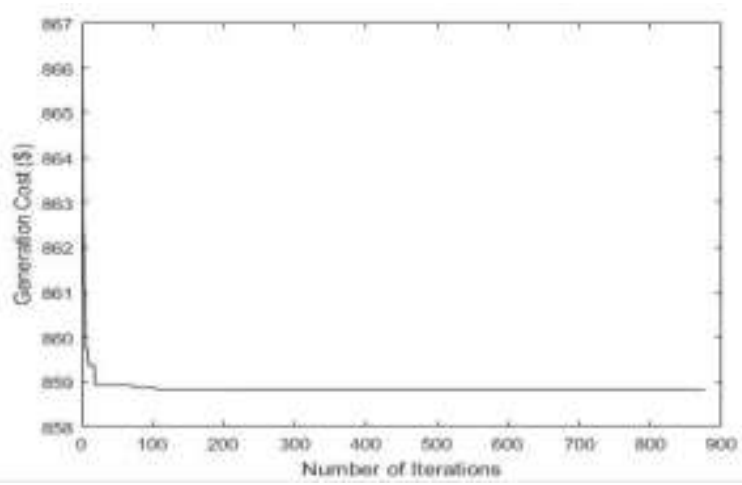

Figure 6: PSO convergence characteristics for real power demand of 200MW for the IEEE 14-bus network demand ranging from 50MW to 250MW. In Figure 3, cost of generation converges at $\$ 366.70$ for power demand of 50MW. In Figure 4, cost of generation converges at $\$ 506.70$ for power demand of $100 \mathrm{MW}$. In figure 5 , cost of generation converges at $\$ 671.70$ for power demand of $150 \mathrm{MW}$. In figure 6 , cost of generation is converged at $\$ 858.81$ for power demand of 200MW. In Figure 7, cost of generation is converged at $\$ 1059.34$ for power demand of 250MW. The results obtained are presented in Table 2 .

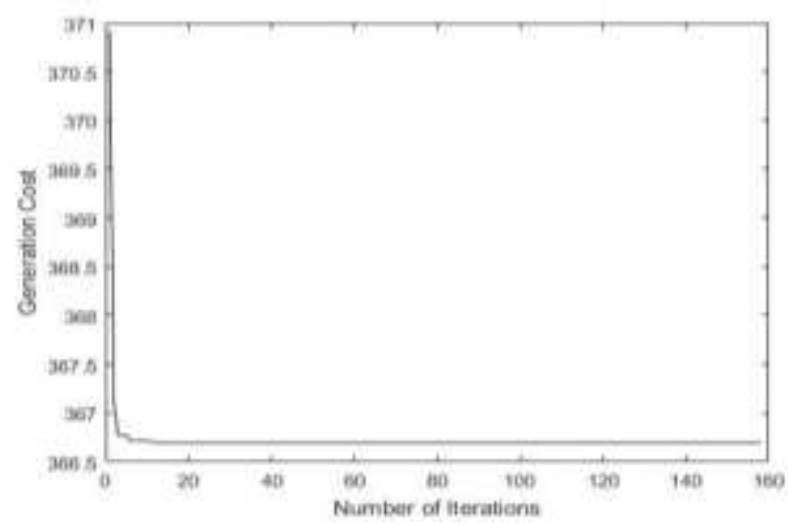

Figure 3:PSO convergence characteristics for real power demand of 50MW for the IEEE 14-bus network

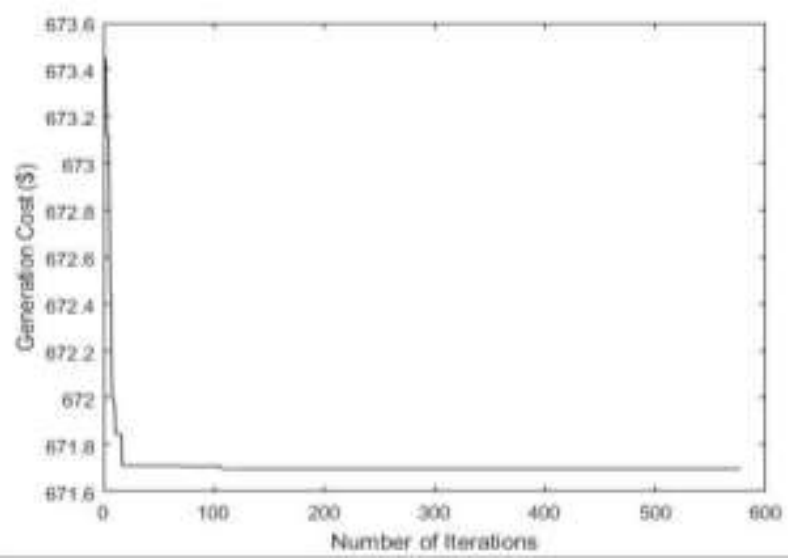

Figure 5: PSO convergence characteristics for real power demand of 150MW for the IEEE 14-bus network

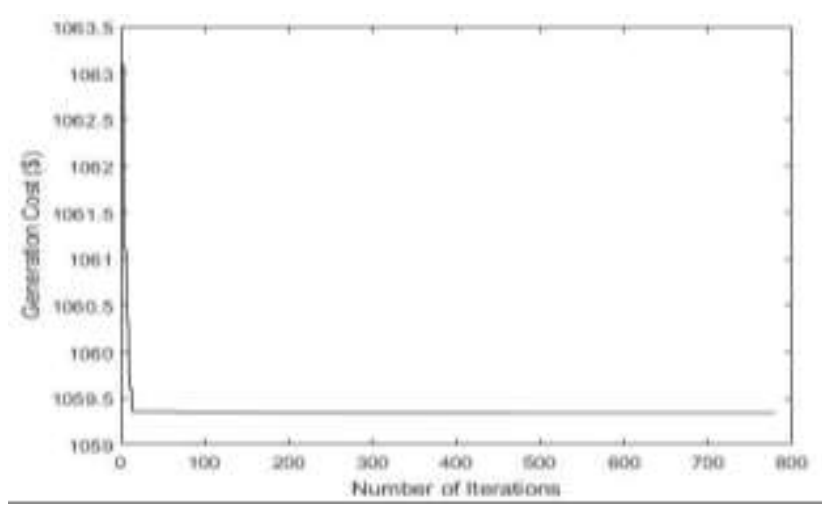

Figure 7: PSO convergence characteristics for real power demand of 250MW for the IEEE 14-bus network 


\subsubsection{Comparison of results}

The results presented for the distribution of real power among the committed generator units for Lambda Iteration and Particle swarm optimization as shown in Table 1 and Table 2 respectively are compared here. Both methods produce the same minimum cost. It can be seen from Figure 2, that Gen3 is maintained at the least power generation irrespective of the power demand. This is as a result of its higher running cost when compared to the other two generators. However, Gen1 is seen to be allocated the highest power generation which means it is has the least running cost when compared to the other two generators. The allocation to Gen1 increased rapidly up to its maximum generation capacity as the power demand increased. Moreover, Gen2 and Gen3 were both kept constant at their minimum generation capacity of 20MW until when the Power Demand rose above 150MW. Hence, this result would assist the system operator in considering the total power demand closely and then apportioning generation to the individual generators to ensure minimum operating cost.

\subsection{Case Study II: IEEE 30-Bus System}

Figure 8 , obtained using the lambda iteration approach displays the power allocation for each generation plant in the IEEE 30-Bus System, for power demand ranging from 50MW to 330MW. The minimum cost obtained using the lambda iteration approach is as presented in Table 3.
Figure 9 to 13, displays the minimum cost obtained using the PSO method on the IEEE 30-Bus System, for power demand ranging from $50 \mathrm{MW}$ to $250 \mathrm{MW}$. In Figure 9, cost of generation converges at $\$ 98.68$ for power demand of 50MW. In Figure 10, cost of generation converges at $\$ 216.30$ for power demand of 100MW. In Figure 11, cost of generation converges at $\$ 357.86$ for power demand of $150 \mathrm{MW}$. In Figure 12 , cost of generation converges at $\$ 529.20$ for power demand of 200MW. In Figure 13, cost of generation converges at $\$ 718.86$ for power demand of $250 \mathrm{MW}$. The result is as presented in Table 4.

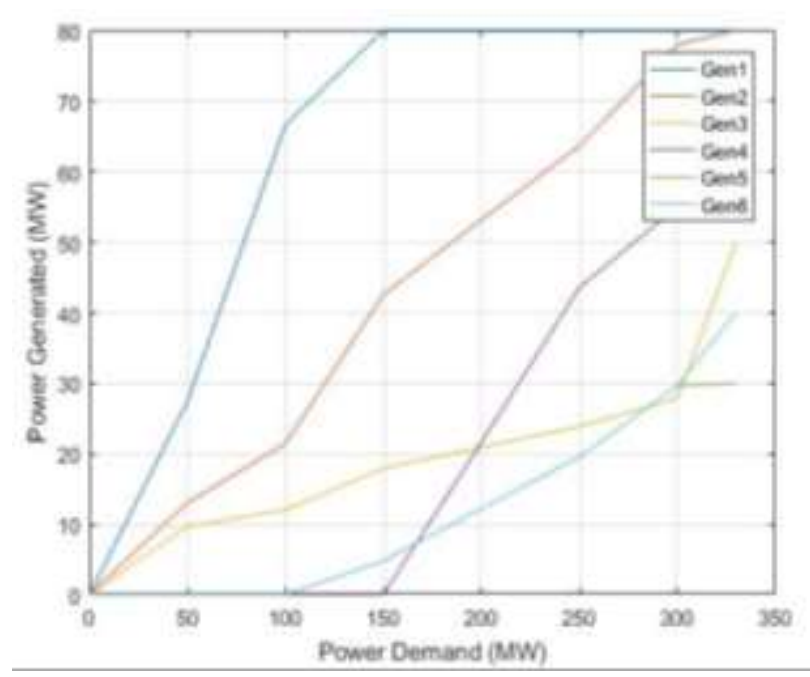

Figure 8: Generator Scheduling for IEEE 30-Bus System

Table 3:minimum cost for a range of power demand using the lambda iteration

\begin{tabular}{cccccccc}
\hline Power Demand & $50 \mathrm{MW}$ & $100 \mathrm{MW}$ & $150 \mathrm{MW}$ & $200 \mathrm{MW}$ & $250 \mathrm{MW}$ & $300 \mathrm{MW}$ & $330 \mathrm{MW}$ \\
\hline Gen 1 & 27 & 67 & 80 & 80 & 80 & 80 & 80 \\
Gen 2 & 13 & 21 & 43 & 53 & 63 & 78 & 80 \\
Gen 3 & 10 & 12 & 18 & 21 & 24 & 28 & 50 \\
Gen 4 & 0 & 0 & 0 & 22 & 43 & 55 & 55 \\
Gen 5 & 0 & 0 & 5 & 12 & 20 & 30 & 30 \\
Gen 6 & 0 & 0 & 5 & 12 & 20 & 30 & 40 \\
\hline Minimum Cost & $\$ 98.68$ & $\$ 216.30$ & $\$ 357.86$ & $\$ 529.20$ & $\$ 718.86$ & $\$ 928.46$ & $\$ 1118.73$ \\
\hline
\end{tabular}

Table 4:Minimum cost for a range of power demand using the Particle Swarm Optimization method

\begin{tabular}{cccccc}
\hline Power Demand & $50 \mathrm{MW}$ & $100 \mathrm{MW}$ & $150 \mathrm{MW}$ & $200 \mathrm{MW}$ & $250 \mathrm{MW}$ \\
\hline Gen 1 & 27 & 67 & 80 & 80 & 80 \\
Gen 2 & 13 & 21 & 43 & 53 & 63 \\
Gen 3 & 10 & 12 & 18 & 21 & 24 \\
Gen 4 & 0 & 0 & 0 & 22 & 43 \\
Gen 5 & 0 & 0 & 5 & 12 & 20 \\
Gen 6 & 0 & 0 & 5 & 12 & 20 \\
\hline Minimum Cost & $\$ 98.68$ & $\$ 216.30$ & $\$ 357.86$ & $\$ 529.20$ & $\$ 718.86$ \\
\hline
\end{tabular}




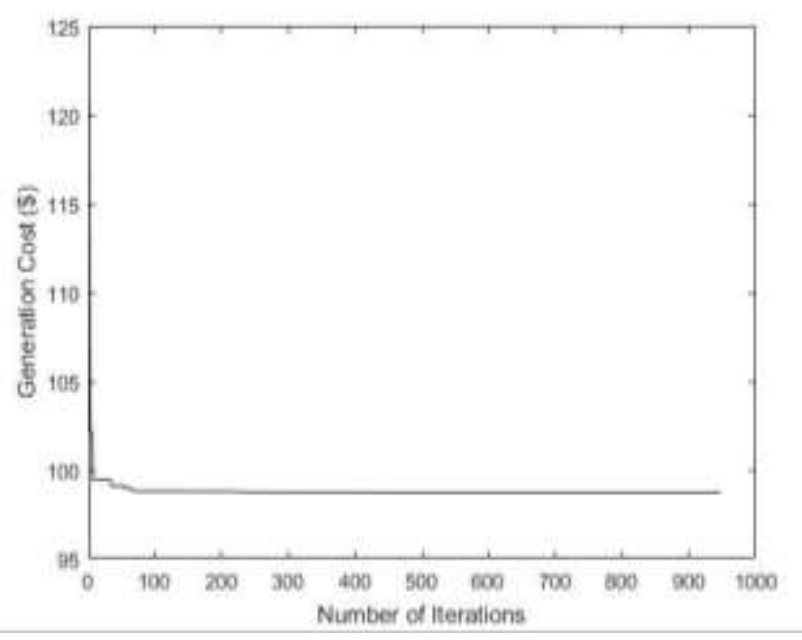

Figure 9: PSO convergence characteristics for real power demand of 50MW for the IEEE 30-bus network

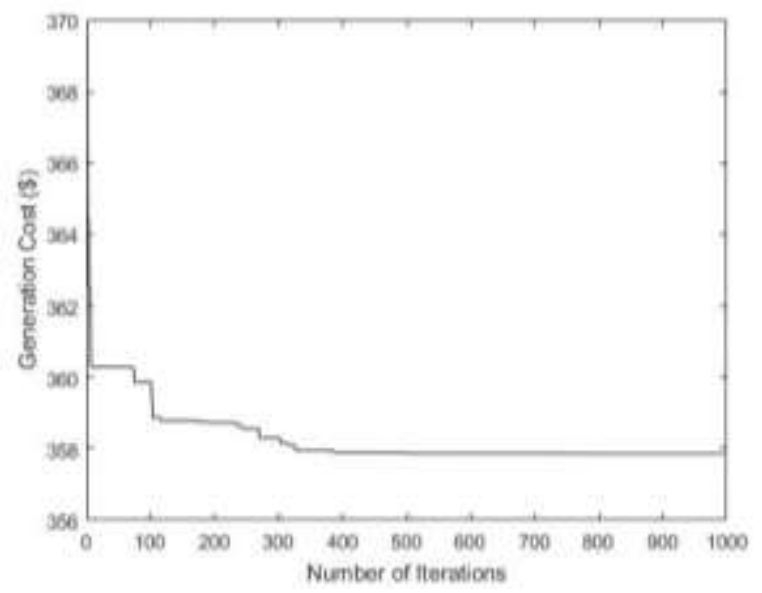

Figure 11: PSO convergence characteristics for real power demand of 150MW for the IEEE 30-bus network

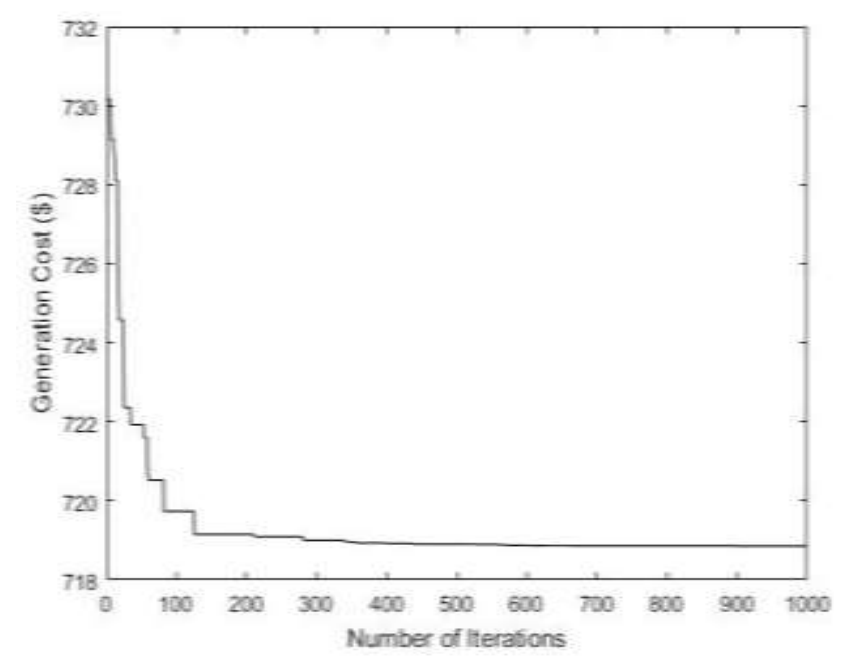

Figure 13: PSO convergence characteristics for real power demand of 250MW for the IEEE 30-bus network

\subsubsection{Comparison of results}

The results presented for the distribution of real power among the committed generator units for

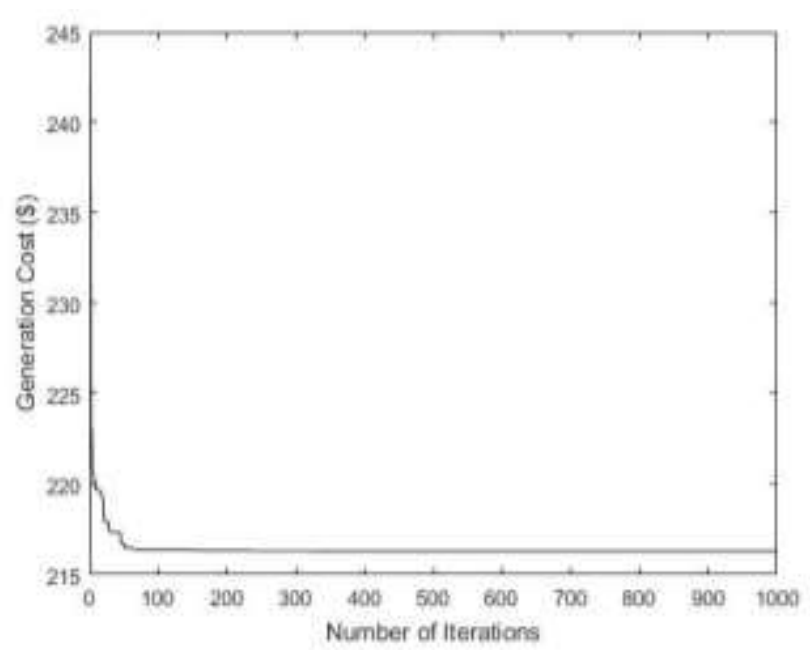

Figure 10: PSO convergence characteristics for real power demand of 100MW for the IEEE 30-bus network

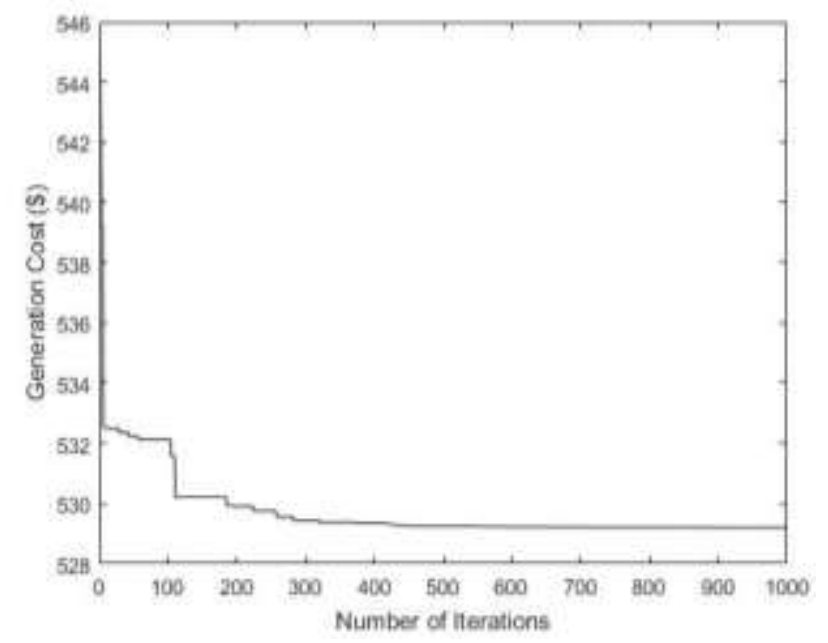

Figure 12: PSO convergence characteristics for real power demand of 200MW for the IEEE 30-bus network

Lambda Iteration and Particle swarm optimization as shown in Table 3 and Table 4 respectively are compared here. The IEEE 30-Bus system contains six generators. From the Economic Dispatch Analysis, the minimum cost of Power generation was determined for a range of Electrical Power Demand. Gen5 and Gen6 have the same cost coefficients; we therefore experience an overlay from the two generators therefore as it can be seen from figure 8. The same consideration is given to the two generators. Again, from the results, Gen1 is to be allocated the highest power generation which means it is has the least running cost when compared to the other five generators. As can be seen from figure 8, the allocation to Gen1 increased rapidly up to its maximum generation capacity as the power demand increased. For power demand of above 150MW, Gen1 is expected to be operated at its maximum generation capacity to ensure minimum cost of generation. Also, Gen5 and Gen6 are allocated the lesser power 
generation. This shows that they have high running/operating cost. This result is therefore beneficial as it would assist the system operator in considering the total power demand closely and then apportioning generation to the individual generators to ensure minimum operating cost. When the power demand on the system was 330MW, Gen5 and Gen6 were operated at their maximum generating capacities which are 30MW and 40MW respectively. As the generation capacity of Gen5 cannot exceed $30 \mathrm{MW}$, it is fixed at that position.

\subsection{Case Study III: Indian 62-Bus System}

Figure 14, obtained using the lambda iteration approach displays the power allocation for each generation plant in the Indian 62-Bus System, for power demand ranging from 650MW to 3900MW. The minimum cost obtained using the lambda iteration approach is as presented in Table 5.

Figure 15 to 19 , displays the minimum cost obtained using the PSO method on the Indian 62-Bus System, for power demand ranging from 1300MW to $3900 \mathrm{MW}$. In Figure 15, cost of generation converges at $\$ 4737.41$ for power demand of $1300 \mathrm{MW}$. In figure 16 , cost of generation converges at $\$ 6820.95$ for power demand of 1950MW. In Figure 17, cost of generation converges at $\$ 10323.68$ for power demand of $2600 \mathrm{MW}$. In figure 18 , cost of generation converges at $\$ 14576.99$ for power demand of $3250 \mathrm{MW}$. In figure 19, cost of generation converges at $\$ 19480.28$ for power demand of $3900 \mathrm{MW}$. The result is as presented in Table 6.

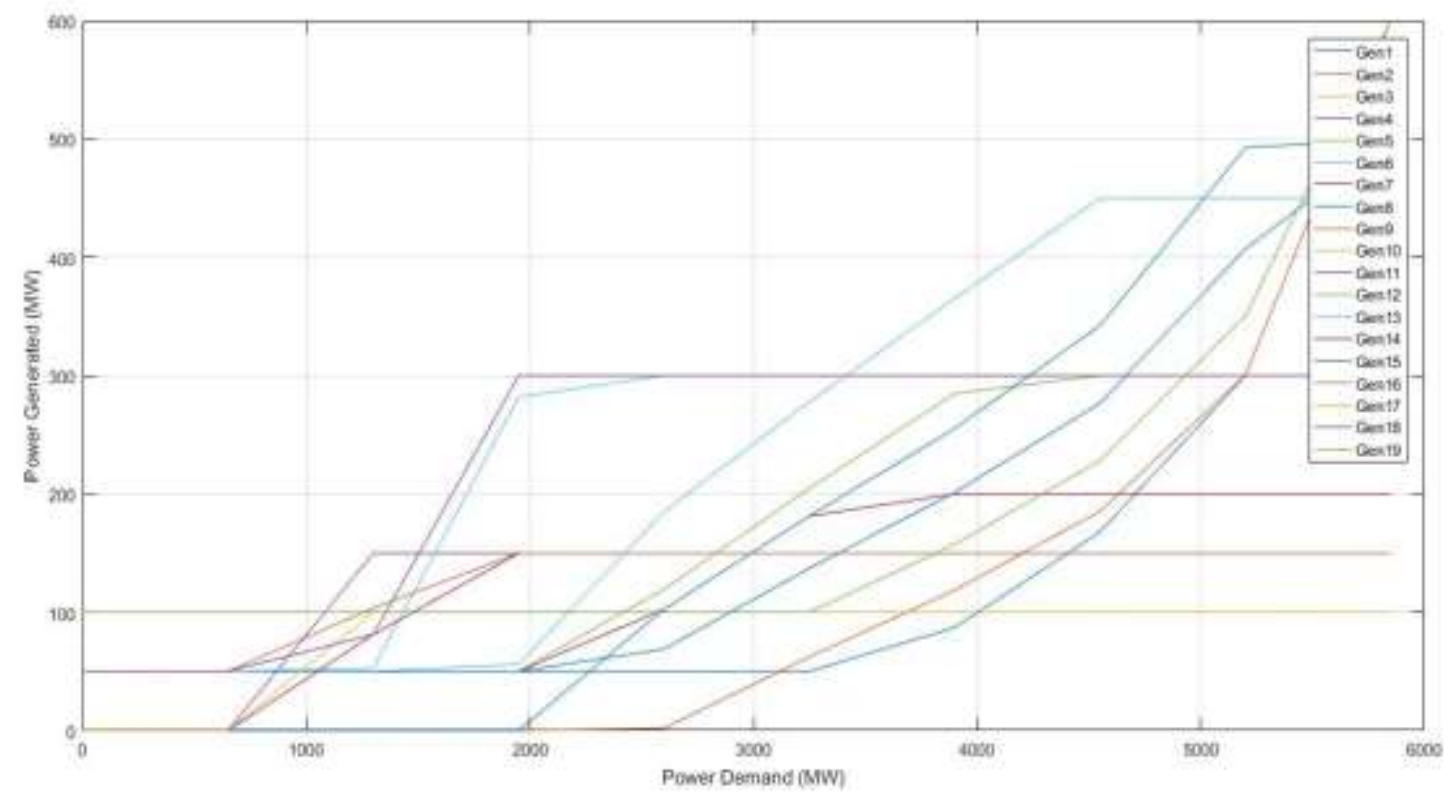

Figure 14: Generator Scheduling for Indian 62-Bus System

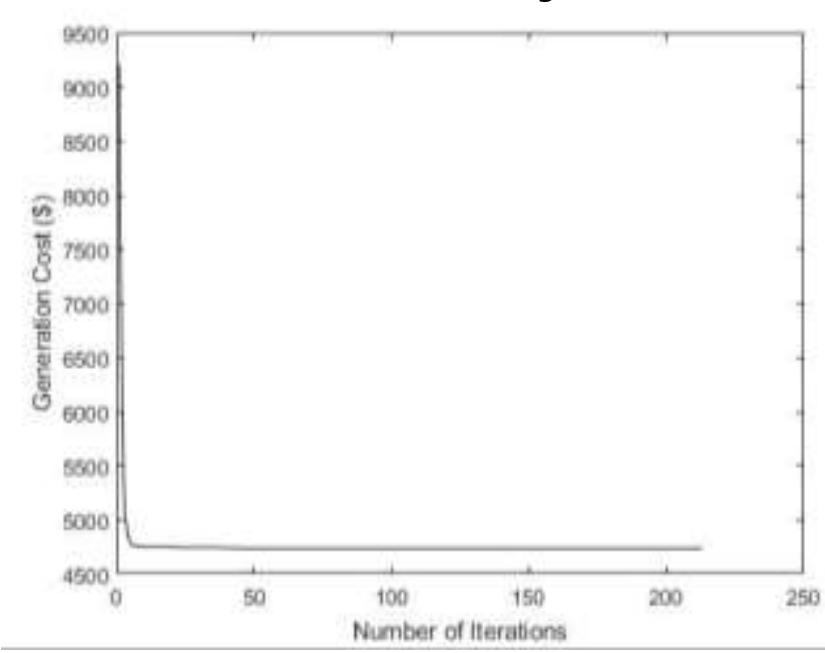

Figure 15: PSO Convergence characteristics for Indian 62-Bus System (Power Demand $=1300 \mathrm{MW}$ )

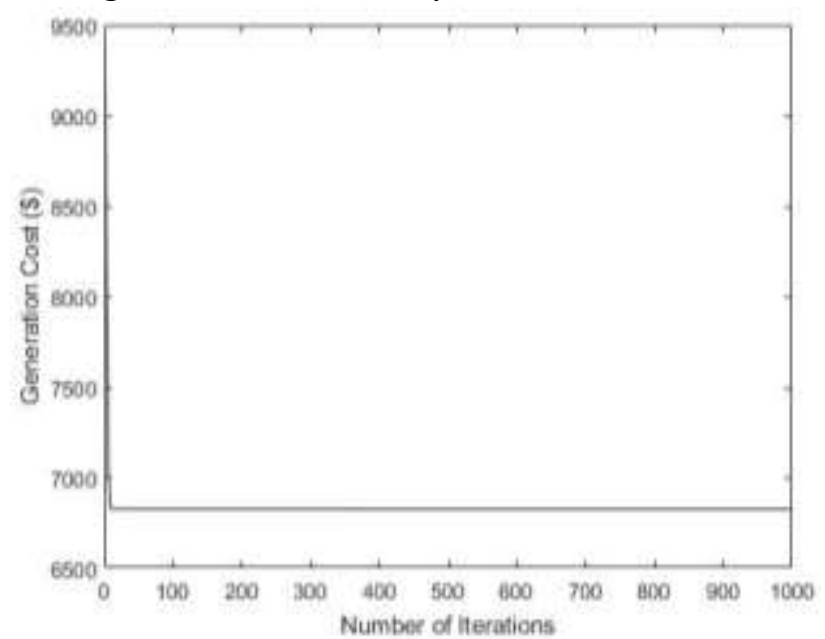

Figure 16: PSO Convergence characteristics for Indian 62-Bus System (Power Demand $=1950 \mathrm{MW}$ ) 
Solving Optimal Generation Dispatch Problem in Power Networks Through Pso and lambda ..., A. S. Alayande, et al

Table 5:Minimum cost for a range of power demand using the Lambda Iteration method

\begin{tabular}{ccccccc}
\hline Power Demand & $650 \mathrm{MW}$ & $1300 \mathrm{MW}$ & $1950 \mathrm{MW}$ & $2600 \mathrm{MW}$ & $3250 \mathrm{MW}$ & $3900 \mathrm{MW}$ \\
\hline Gen 1 & 50 & 50 & 50 & 50 & 50 & 87 \\
Gen 2 & 50 & 50 & 56 & 185 & 278 & 365 \\
Gen 3 & 50 & 50 & 56 & 185 & 278 & 365 \\
Gen 4 & 0 & 150 & 150 & 150 & 150 & 150 \\
Gen 5 & 50 & 50 & 50 & 119 & 205 & 285 \\
Gen 6 & 50 & 50 & 56 & 185 & 278 & 365 \\
Gen 7 & 50 & 50 & 50 & 103 & 181 & 200 \\
Gen 8 & 50 & 50 & 50 & 69 & 137 & 201 \\
Gen 9 & 0 & 0 & 0 & 2 & 62 & 119 \\
Gen 10 & 0 & 100 & 100 & 100 & 100 & 100 \\
Gen 11 & 50 & 81 & 150 & 150 & 150 & 150 \\
Gen 12 & 0 & 100 & 100 & 100 & 100 & 100 \\
Gen 13 & 50 & 53 & 282 & 300 & 300 & 300 \\
Gen 14 & 0 & 81 & 150 & 150 & 150 & 150 \\
Gen 15 & 0 & 0 & 0 & 103 & 181 & 255 \\
Gen 16 & 50 & 103 & 150 & 150 & 150 & 150 \\
Gen 17 & 0 & 100 & 100 & 100 & 100 & 100 \\
Gen 18 & 50 & 81 & 300 & 300 & 300 & 300 \\
Gen 19 & 100 & 100 & 100 & 100 & 100 & 157 \\
\hline Minimum Cost & $\$ 3849.00$ & $\$ 4737.59$ & $\$ 6822.96$ & $\$ 10328.90$ & $\$ 14583.07$ & $\$ 19484.89$ \\
\hline
\end{tabular}

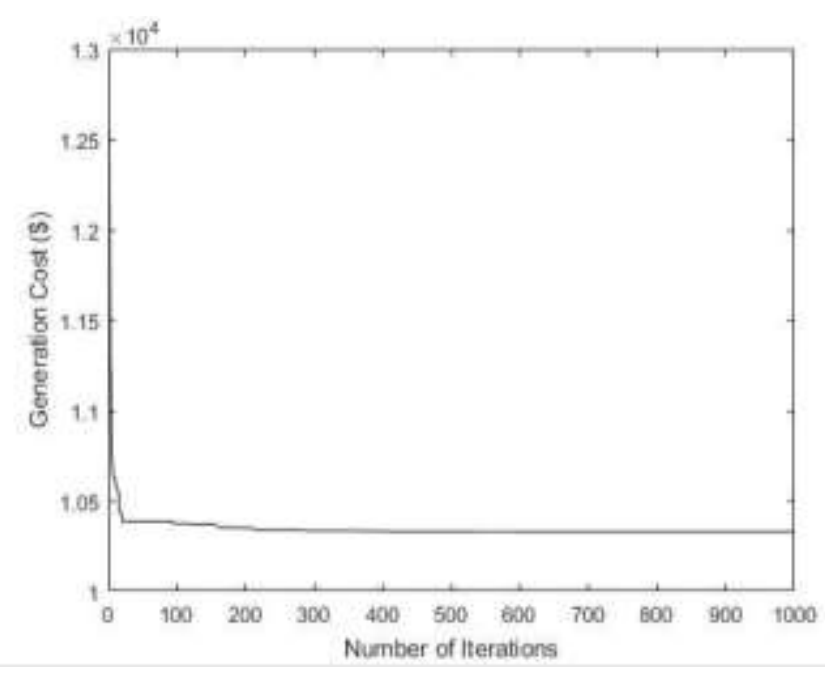

Figure 17: PSO Convergence characteristics for Indian 62-Bus System (Power Demand = 2650MW)

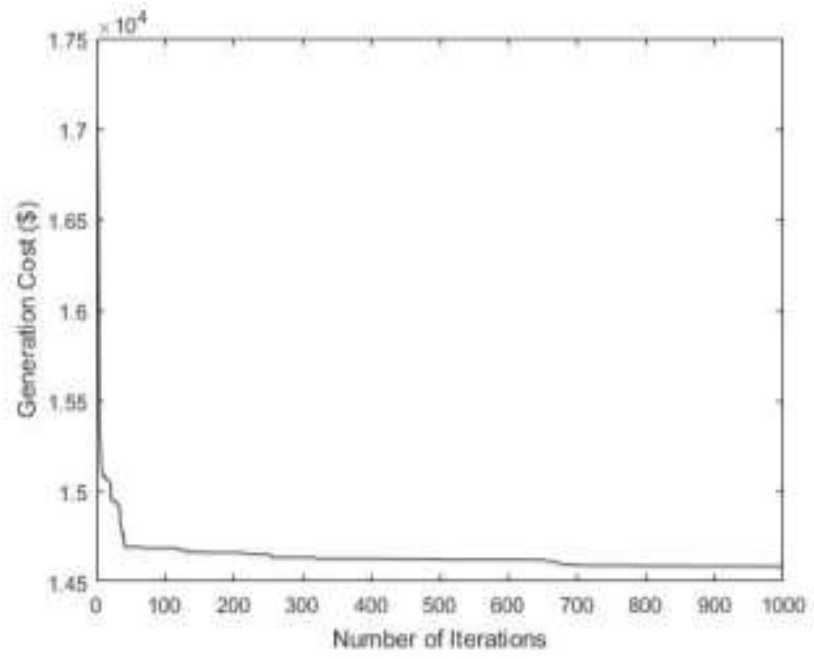

Figure 18: PSO Convergence characteristics for Indian 62-Bus System (Power Demand = 3250MW)

Table 6: Minimum cost for a range of power demand using the Particle Swarm Optimization method

\begin{tabular}{llllll}
\hline Power Demand & $1300 \mathrm{MW}$ & $1950 \mathrm{MW}$ & $2600 \mathrm{MW}$ & $3250 \mathrm{MW}$ & $3900 \mathrm{MW}$ \\
\hline Gen 1 & 50 & 50 & 50 & 50 & 90 \\
Gen 2 & 50 & 58 & 187 & 280 & 366 \\
Gen 3 & 50 & 58 & 187 & 280 & 366 \\
Gen 4 & 150 & 150 & 150 & 150 & 150 \\
Gen 5 & 50 & 50 & 117 & 207 & 300 \\
Gen 6 & 50 & 50 & 181 & 279 & 365 \\
Gen 7 & 50 & 50 & 104 & 181 & 200 \\
Gen 8 & 50 & 50 & 69 & 133 & 195 \\
Gen 9 & 0 & 0 & 0 & 60 & 115 \\
Gen 10 & 100 & 100 & 100 & 100 & 100 \\
Gen 11 & 82 & 150 & 150 & 150 & 150 \\
Gen 12 & 100 & 100 & 100 & 100 & 100 \\
Gen 13 & 50 & 285 & 300 & 300 & 300
\end{tabular}


Solving Optimal Generation Dispatch Problem in Power Networks Through Pso and lambda ..., A. S. Alayande, et al

\begin{tabular}{llllll}
\hline Power Demand & $1300 \mathrm{MW}$ & $1950 \mathrm{MW}$ & $2600 \mathrm{MW}$ & $3250 \mathrm{MW}$ & $3900 \mathrm{MW}$ \\
\hline Gen 14 & 82 & 150 & 150 & 150 & 150 \\
Gen 15 & 0 & 0 & 104 & 179 & 250 \\
Gen 16 & 104 & 150 & 150 & 150 & 150 \\
Gen 17 & 100 & 100 & 100 & 100 & 100 \\
Gen 18 & 82 & 300 & 300 & 300 & 300 \\
Gen 19 & 100 & 100 & 100 & 100 & 154 \\
\hline Minimum Cost & $\$ 4737.41$ & $\$ 6820.95$ & $\$ 10323.68$ & $\$ 14576.99$ & $\$ 19480.28$ \\
\hline
\end{tabular}

\subsubsection{Comparison of results}

The results presented for the distribution of real power among the committed generator units for Lambda Iteration and Particle swarm optimization as shown in Table $V$ and Table VI respectively are compared here. The Indian 62-Bus system contains six generators. The Particle Swarm Optimization is seen to converge at a lower total cost of generation compared to Lambda Iteration. Hence, it proves to be superior to Lambda iteration as it achieves a more economical scheduling of generators with the least cost of operation. From the results, Gen4, 10, 12 and 17 have low running cost and thus, they are to be operated at their maximum capacity for power demand of $650 \mathrm{MW}$ and above to ensure minimum operating cost. Gen 9 and Gen 15 were both operated at off position until the demand for power rose above 1950MW.

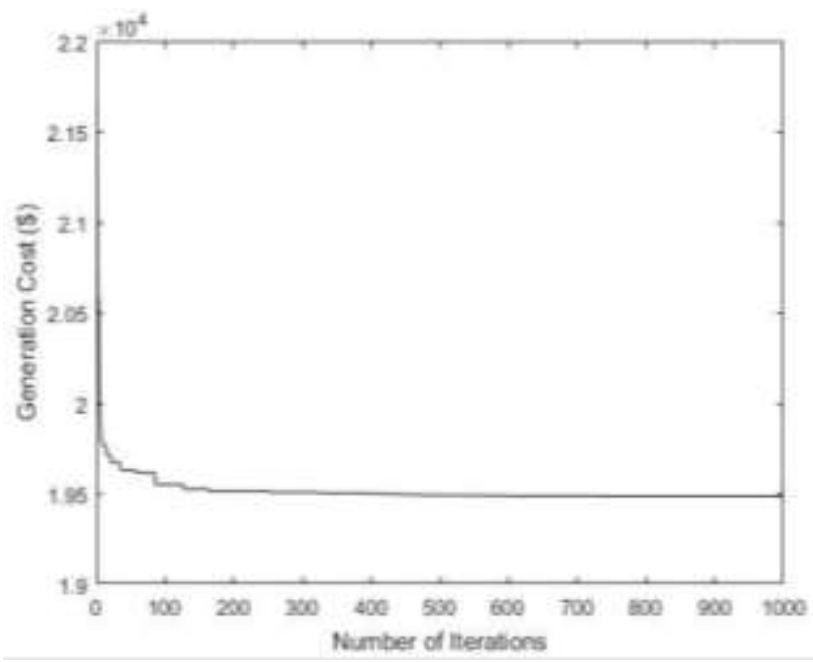

Figure 19: PSO Convergence characteristics for Indian 62-Bus System (Power Demand = 3900MW)

\subsection{Marginal (Incremental) Cost Curve}

The cost function is expressed as a quadratic function of active power as given in (15). The derivative of the cost curve is the marginal or incremental cost curve as expressed in (16). The marginal (incremental) cost is one of the most important quantities in operating a power system. It informs us of the cost of producing the next increment of power (the next MW). It is a measure of how costly it will be to produce the next increment of power.

After Economic dispatch, the marginal or incremental cost of all generating units is equal. This incremental cost is the Lagrangian multiplier, $\lambda$ and is the system wide cost of generating electricity. It is the price charged to customers. The table shows the incremental cost is calculated for a range of power demand.

From the results obtained from case study I, it can be seen that for a power demand of 50MW, the incremental cost is $\$ 2.55$. So, if the power demand is increased by $1 \mathrm{MW}$ from $50 \mathrm{MW}$ to $51 \mathrm{MW}$, the cost of generation increases by $\$ 2.55$. However, if power demand keeps increasing by $1 \mathrm{MW}$, the incremental cost will not be the same. Hence, there is need to recalculate.

For a power demand of $100 \mathrm{MW}$, the incremental cost is $\$ 3.05$. So, if the power demand is increased by $1 \mathrm{MW}$ from $100 \mathrm{MW}$ to $101 \mathrm{MW}$, the cost of generation increases by $\$ 3.05$.

Table 7: IEEE Standard 14-Bus System

\begin{tabular}{c|cccccc}
\hline Power Demand & $50 \mathrm{MW}$ & $100 \mathrm{MW}$ & $150 \mathrm{MW}$ & $200 \mathrm{MW}$ & $250 \mathrm{MW}$ & $290 \mathrm{MW}$ \\
\hline Marginal Cost $(\$ / \mathrm{MWh})$ & 2.55 & 3.05 & 3.55 & 3.88 & 4.15 & 4.39 \\
\hline
\end{tabular}

Table 8: IEEE Standard 30-Bus System

\begin{tabular}{cccccccc}
\hline Power Demand & $50 \mathrm{MW}$ & $100 \mathrm{MW}$ & $150 \mathrm{MW}$ & $200 \mathrm{MW}$ & $250 \mathrm{MW}$ & $300 \mathrm{MW}$ & $335 \mathrm{MW}$ \\
\hline $\begin{array}{c}\text { Marginal Cost } \\
(\$ / \mathrm{MWh})\end{array}$ & 2.21 & 2.50 & 3.24 & 3.61 & 3.98 & 4.48 & 7.25 \\
\hline
\end{tabular}


Table 9: Indian Standard 62-Bus System

\begin{tabular}{llllllllll}
\hline Power Demand (MW) & 650 & 1300 & 1950 & 2600 & 3250 & 3900 & 4550 & 5200 & 5850 \\
\hline Marginal Cost \$/MWh & 0.50 & 2.33 & 4.62 & 6.03 & 7.06 & 8.02 & 9.15 & 11.10 & 16.20 \\
\hline
\end{tabular}

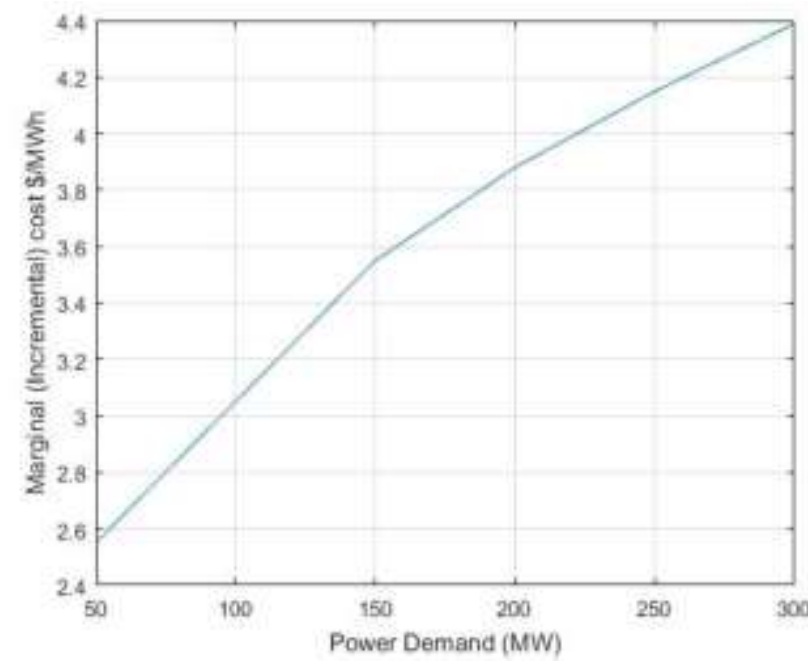

Figure 20: Marginal incremental cost curve in a 14-bus network

From the results obtained from case study II, it can be seen that for a power demand of 50MW, the incremental cost is $\$ 2.21$. So, if the power demand is increased by $1 \mathrm{MW}$ from $50 \mathrm{MW}$ to $51 \mathrm{MW}$, the cost of generation increases by $\$ 2.21$. However, if power demand keeps increasing by $1 \mathrm{MW}$, the incremental cost will not be the same. Hence, there is need to recalculate. For a power demand of $100 \mathrm{MW}$, the incremental cost is $\$ 2.50$.

So, if the power demand is increased by $1 \mathrm{MW}$ from $100 \mathrm{MW}$ to $101 \mathrm{MW}$, the cost of generation increases by $\$ 2.50$. The huge steep between 300MW and $330 \mathrm{MW}$ arises because a generator with greater running cost is used to meet up with the increase in power demand.

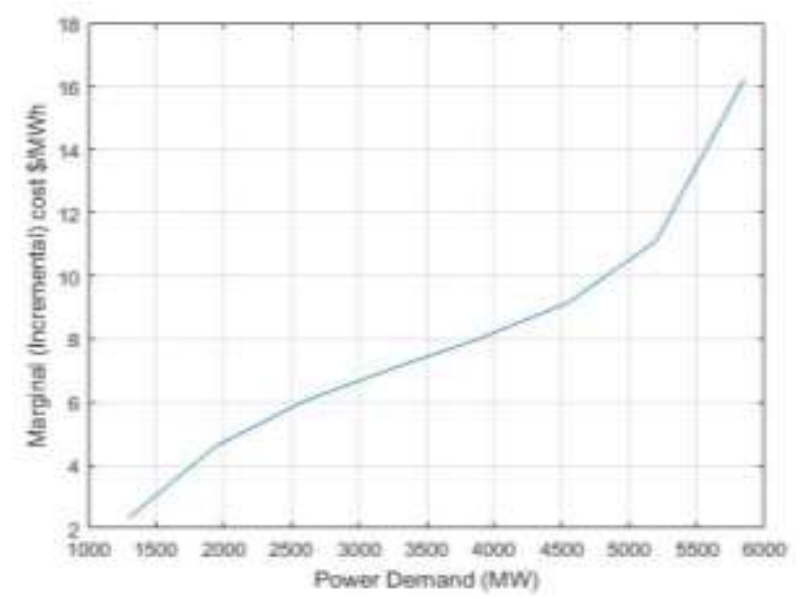

Figure 22: Marginal incremental cost curve in a 62bus network

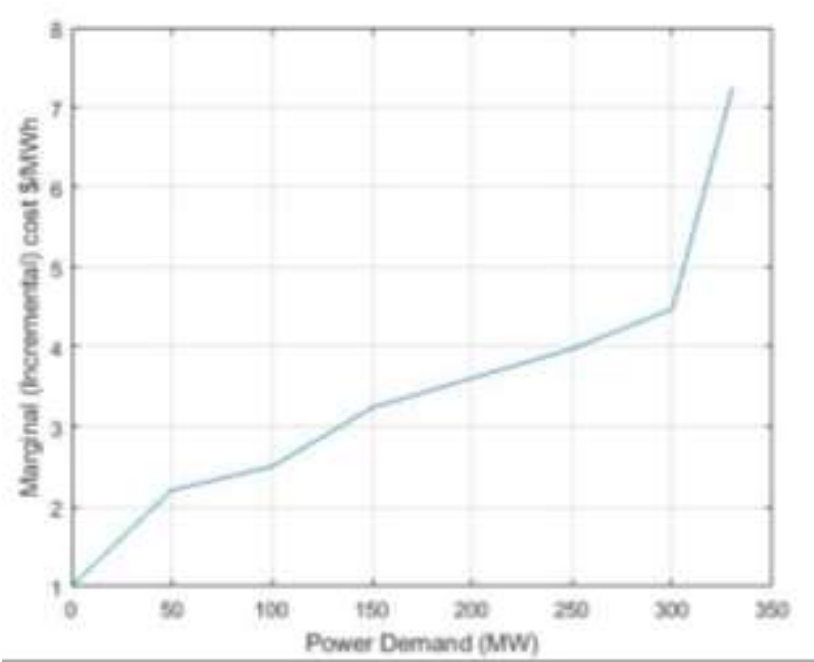

Figure 21: Marginal incremental cost curve in a 30bus network

From the results obtained from case study III, it can be seen that for a power demand of 2600MW, the incremental cost is $\$ 6.03$. So, if the power demand is increased by $1 \mathrm{MW}$ from $2600 \mathrm{MW}$ to $2601 \mathrm{MW}$, the cost of generation increases by $\$ 6.03$. However, if power demand keeps increasing by $1 \mathrm{MW}$, the incremental cost will not be the same. Hence, there is need to recalculate. For a power demand of $3250 \mathrm{MW}$, the incremental cost is $\$ 7.06$. So, if the power demand is increased by $1 \mathrm{MW}$ from $3250 \mathrm{MW}$ to $3251 \mathrm{MW}$, the cost of generation increases by $\$ 7.06$. For Power demand greater than 5850MW, the incremental cost is Infinity. This is because the demand is now above the Total generation capacity.

\section{CONCLUSION}

In this study, lambda iteration method and Particle Swarm Optimization method for solving problem of economic dispatch have been examined. The minimum cost of Power generation was determined for a range of Electrical Power Demand. The PSO algorithm displays a more economical solution, compared to what was obtained using lambda iteration, and stable convergence. Result reveals that both techniques are efficient and cost effective in ensuring optimal operation of the plants giving rise to improved cost savings. The lambda iteration method provides us with the next incremental cost of generation on every power demand which is very useful for utility companies as it is the per unit price 
charged to customers. The PSO displays high quality convergence characteristics.

\section{REFERENCES}

[1] D. W. C. Sunny Orike, "Constrained Elitist Genetic Algorithm for Economic Load Dispatch: Case Study on Nigerian Power System," International Journal of Computer Applications, vol. 76, no. 5, pp. 27-33, 2013.

[2] Y. S. Haruna, Y. A. Yisah, G. A. Bakare, M. S. Haruna, and S. O. Oodo, "Optimal Economic Load Dispatch of the Nigerian Thermal Power Stations Using Particle Swarm Optimization ( PSO )," Ijes, vol. 6, no. 1, pp. 17-23, 2017.

[3] S. A. Mnse, E. O. O. Babayomi, and U. Damisa, "Optimal Dispatch of Generation: Case Study," 2012.

[4] E. Buraimoh, T. O. Ejidokun, and O. J. Ayamolowo, "Optimization of an Expanded Nigeria Electricity Grid System using Economic Load Dispatch," $A B \cup A D$ Journal of Engineering Research and Development, vol. 1, no. 1, pp. 61-66, 2017.

[5] V. Kumar, J. Saraswat, and M. Tech, "A Review on Optimization Techniques for Economic Load Dispatch Problem," International Research Journal of Engineering and Technology, vol. 3, no. 7, pp. 375379, 2016.

[6] M. Z. Elahe Faghihnia, Sadegh Khaleghi, Reihane Kardehi Moghaddam, "Particle swarm optimization of economic dispatch problem: A brief review transfer," in 2015 12th International Conference on Informatics in Control, Automation and Robotics (ICINCO), vol. 1, pp. 72-77, 2015.

[7] X. Xia and A. M. Elaiw, "Optimal dynamic economic dispatch of generation: A review," Electric Power Systems Research, vol. 80, no. 8, pp. 975-986, 2010.

[8] R. Ramanathan, "Fast Economic Dispatch Based on the Penalty Factors From Newton'S Method.," IEEE transactions on power apparatus and systems, vol. PAS-104, no. 7, pp. 1624-1629, 1985.

[9] D. O. Dike, M. I. Adinfono, and G. Ogu, "Economic Dispatch of Generated Power Using Modified LambdaIteration Method," IOSR Journal of Electrical and Electronics Engineering (IOSR-JEEE), vol. 7, no. 1, pp. 49-54, 2013.

[10] H. Xing, Z. Lin, M. Fu, A. Basics, and G. Theory, "Distributed Augmented Lambda-iteration Method For Economic Dispatch in Smart Grid," in 2017 Chinese Automation Congress (CAC), 2017.

[11] Z. L. Gaing, "Particle swarm optimization to solving the economic dispatch considering the generator constraints," IEEE Transactions on Power Systems, vol. 18, no. 3, pp. 1187-1195, 2003.

[12] V. Hosseinnezhad and E. Babaei, "Economic load dispatch using $\theta-P S O$," International Journal of Electrical Power and Energy Systems, vol. 49, no. 1, pp. 160-169, 2013.
[13] K. Dasgupta and S. Banerjee, "An Analysis of Economic Load Dispatch using Different Algorithms," in Proceedings of 2014 1st International Conference on Non Conventional Energy (ICONCE 2014), 2014, pp. 216-219.

[14] A. Olurotimi and K. Folly, "Comparison of Economic Load Dispatch of Nigeria Thermal Plants Using Genetic Algorithm and Differential Evolution Methods," in Southern Africa Universities Power Engineering Conference (SAUPEC 2015), 2015, no. June.

[15] I. Ciornei and E. Kyriakides, "A GA-API Solution for the Economic Dispatch of Generation in Power System Operation," IEEE Transactions on Power Systems, vol. 27, no. 1, pp. 233-242, 2012.

[16] W. Lin, F. Cheng, and M. Tsay, "An Improved Tabu Search for Economic Dispatch," Power, vol. 17, no. 1, pp. 108-112, 2002.

[17] H. Happ, "Optimal Power Dispatch," IEEE Transactions on Power Apparatus and Systems, vol. PAS-93, no. 3, pp. 820-830, 1974.

[18] C. L. H. Lin,C. E.; S. T. Chen, "A Direct NewtonRaphson Economic Dispatch," Transactions on Power System, vol. 7, no. 3, pp. 1149-1154, 1992.

[19] C. Chen and N. Chen, "Constraints," Power, vol. 16, no. 4, pp. 764-769, 2001.

[20] C. K. Panigrahi, P. K. Chattopadhyay, R. N. Chakrabarti, and M. Basu, "Simulated Annealing Technique for Dynamic Economic Dispatch," Electric Power Components and Systems, vol. 34, no. 5, pp. 577-586, 2006.

[21] N. Li, C. Zhao, and L. Chen, "Connecting automatic generation control and economic dispatch from an optimization view," IEEE Transactions on Control of Network Systems, vol. 3, no. 3, pp. 254-264, 2016.

[22] I. N. Trivedi et al., "Economic Load Dispatch Problem with Ramp Rate Limits and Prohibited Operating Zones Solve using Levy Flight Moth-Flame Optimizer," in 2016 International Conference on Energy Efficient Technologies for Sustainability (ICEETS), , pp. 442447, 2016.

[23] D. Santra, A. Mondal, A. Mukherjee, and K. Sarker, "Hybrid PSO - ACO technique to solve economic load dispatch problem," in 2015 IEEE International Conference on Research in Computational Intelligence and Communication Networks, ICRCICN 2015, 2015, pp. 187-191.

[24] Y. Ç. Kuyu and N. Erdem, "Solving economic load dispatch problem using vortex search algorithm," 2017 10th International Conference on Electrical and Electronics Engineering (ELECO), pp. 1-5, 2017.

[25] H. Saadat, "Power System analysis," Power system analysis. pp. 353-381, 2010.

[26] "DATA SHEETS FOR IEEE BUS SYSTEM." 